\title{
Severe Dilated Cardiomyopathy Due to Polycythemia Vera - A Rare Etiology
}

\author{
Muhammad Imran Butt ${ }^{1 *}$ and Mudassar Latif ${ }^{2}$ \\ ${ }^{1}$ Medical Registrar, Sir Charles Gairdner Hospital Western Australia, Australia \\ ${ }^{2}$ Advance Trainee Geriatrics, Sir Charles Gairdner Hospital Western Australia, Australia
}

Submission: October 28, 2019; Published: November 05, 2019

*Corresponding author: Muhammad Imran Butt, Department of Medicine, Sir Charles Gairdner Hospital Hospital Avenue, Nedlands, Perth, WA, 6009, Australia

\section{Abstract}

Polycythemia vera (PV) is a myeloproliferative disorder characterised by panhyperplastic bone marrow with most prominent feature of increased red cell mass resulting from excessive erythropoiesis. This translates to sludging of blood flow due to hyperviscosity and thrombosis leading to poor oxygen delivery to tissues. Thrombosis of cardiovascular system is extremely rare in PV with limited data available in literature. We describe a case of a 40-year old gentleman with new onset of severely dilated cardiomyopathy secondary to PV. The likely pathophysiological mechanism is the necrosis of the cardiac myocytes due to micro-thrombi.

Keywords: Cardiomyopathy; Polycythemia vera; Heart failure

\section{Case Report}

A 40-year old gentleman presented with history of exertional dyspnoea over 2 months. He had decreased exercise tolerance from New York Hear Association class I to class III in 2 months. He also reported orthopnea and paroxysmal dyspnoea for last 2 weeks of his presentation. He did not report any chest pain, palpitations, diaphoresis or dizziness. He had no symptoms of cough, fever, weight loss or any other symptoms to suggest systemic infection. He had no significant past medical or surgical history and was not taking any medications. Family history did not reveal any cardiac diseases including any sudden deaths. He never smoked cigarettes and consumed alcoholic occasionally. There was no history of drug abuse and did not report of having excessive energy drinks.

On examination, his respiratory rate was 18 , pulse rate 70 and regular with blood pressure of 125/85 and was afebrile.

Cardiovascular examination revealed a displaced apex beat with dual heart sounds and no murmurs. Jugular venous pulse was not elevated and had bi basal coarse crackels on auscultation of his chest. Abdominal examination did not reveal any organomegaly and there was no peripheral edema.

Blood tests showed haemoglobin of $19.5 \mathrm{~g} / \mathrm{dl}$ with haemocrit of $51.5 \%$ and normal platelets and white cell counts. The diagnosis of polycythemia vera was confirmed on the basis of positive JAK2 mutation.

Chest $\mathrm{X}$ ray showed cardiomegaly with mild interstitial edema. A trans-thoracic echocardiogram showed severe dilated cardiomyopathy with ejection fraction of $18 \%$.

He underwent a coronary angiogram which showed normal coronary arteries ruling out ischemic cardiomyopathy. Other blood tests including comprehensive metabolic panel, thyroid functions, genetic screening and urine toxicology screening were all within normal limits.

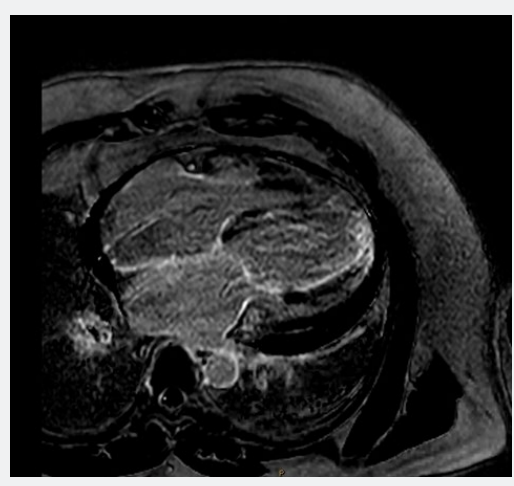

Figure 1: Extensive fibrosis of myocardium. 


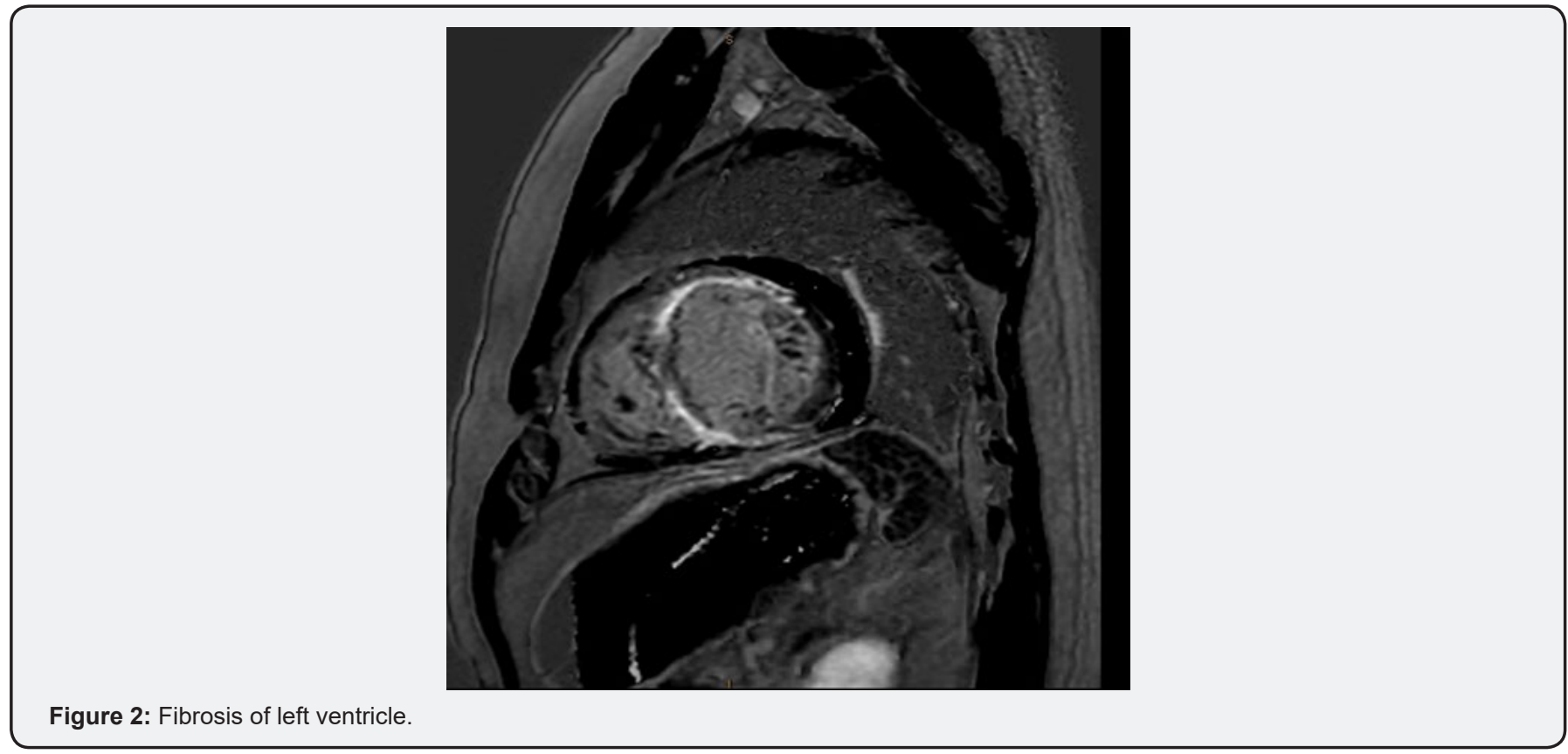

A magnetic resonance imaging (MRI) of heart revealed widespread enhancing fibrous replacement of the left ventricular myocardium most extensive in anterior wall, inferior wall and apex (Figure $1 \& 2$ ) with high grade subepicardial to near- transmural involvement and mild hypokinesis of the right ventricular free wall with some thinning of the apex, but no significant delayed hyper-enhancement. Ejection fraction was $17 \%$ and there was no valvular pathology. A rare diagnosis of cardiomyopathy due to PV was suspected. However, patient refused to undergo an endomyocardial biopsy to confirm the diagnosis.

For polycthemia he was started on Aspirin 100mg daily and weekly phlebotomy. For cardiomyopathy he was commenced on Ramipril and Bisoprolol with dose up titration regimen. He also required intravenous frusemide during admission and 40mg oral tablet on discharge. A regular follow up after 3 months showed markedly improved symptoms and echocardiogram showed improved ejection fraction to $42 \%$. Patient has regular follow up with cardiology and haematology.

\section{Discussion}

Polycythemia vera is a rare chronic myeloproliferative disorder manifested by clonal proliferation of morphologically variable myeloid cells with different haematopoietic efficiency and is distinguished from other myeloproliferative disorders by elevated red cell mass. Patients with PV have increased risk of both arterial and venous thrombosis as well as haemorrhage.

Although the exact mechanism of hypercoagulability is not clear, abnormalities in blood viscosity, leukocytes and platelets have been implicated [1]. Thrombosis in the large vessels is a rare complication. Very few cases have been reported in literature with massive intra-cardiac thrombi leading to heart failure $[2,3]$. In international literature, there is only one biopsy proven case reported with dilated cardiomyopathy secondary to microvascular thrombosis and hyperviscosity [4]. There was also a case of Takotsubo cardiomyopathy associated with PV which was believed to be due platelet-mediated adrenaline release from massive thrombocytosis acting as a physical stressor [5].

Although our patient denied to consent for endomyocardial biopsy, the absence of intra-cardiac thrombosis or the features of takotsubo cardiomyopathy on echocardiogram makes the hypothesis of microvascular myocytes necrosis as the only possible pathophysiology of cardiomyopathy. However, the direct association of $\mathrm{PV}$ with dilated cardiomyopathy is not straightforward and requires the exclusion of other possible causes. As our patient underwent all investigations and other possible aetiologies were ruled out, the diagnosis of dilated cardiomyopathy secondary to PV is likely. The only other possibility would be idiopathic cardiomyopathy in a patient of polycythemia vera.

Chronic oxidative stress results in fibrosis of the myocardium [6] which in ischemic cardiomyopathy starts subendocardially and then progresses to transmural and the subendocardial region unlike non-ischemic cardiomyopathy which is often epicardial rather than trans-mural or subendocardial $[7,8]$.

Considering the previous case reports proving the association of cardiomyopathy with haematological diseases [4,9] and absence of other causes indicates a direct association of PV with dilated cardiomyopathy.

\section{Conclusion}

Polycythemia vera is a rare aetiology of cardiomyopathy not often seen in literature and should be considered in patients 
with previous history or new diagnosis of PV associated with heart failure. The recognition of this association will determine treatment and prognosis in such patients.

We hope that this case along with others will bring forward similar observations in future and help in better understanding the pathophysiology and management of heart failure in patient with polycythemia vera.

\section{Author Contributions}

Muhammad Imran Butt - Acquisition of data, Drafting the article, Substantial contributions to conception and study design, Analysis and interpretation of data, revising it critically for important intellectual content, Final approval of the version to be published.

Mudassar Latif - Revising it critically for important intellectual content, Analysis and interpretation of data.

\section{References}

1. Landolfi R, Di Gennaro L, Falanga A (2008) Thrombosis in myeloproliferative disorders: pathogenetic facts and speculation. Leukemia 22(11): 2020-2028.
2. Ali M, Fayemi AO, Malcolm D, Braun EV (1980) Intraventricular thrombosis in polycythemia vera: a cause of intractable cardiac failure. Am Heart J 100(4): 520-522.

3. Yuan SM, Shinfeld A, Raanani E (2009) Massive intraventricular thrombus in polycythemia vera. J Card Surg 24(2): 110-112.

4. Konopka A, Stepinska J, Banaszewski M, Szajewski T (1998) [A case of dilated cardiomyopathy caused by myocardial microinfarcts in the course of polycythemia vera]. Pol Merkur Lekarski 4(19): 26-28.

5. Sijan Basnet, Priya Rajagopalan, Rashmi Dhital, Biswaraj Tharu (2018) Takotsubo Cardiomyopathy Associated with Polycythemia Vera. Case Reports in Cardiology 2018(4542925): 4.

6. Neglia D, Michelassi C, Trivieri MG, Sambuceti G, Giorgetti A, et al. (2002) Prognostic role of myocardial blood flow impair- ment in idiopathic left ventricular dysfunction. Circulation 105(2): 186-193.

7. Mahrholdt H, Wagner A, Judd RM, Sechtem U, Kim RJ (2005) Delayed enhancement cardiovascular magnetic resonance assessment of nonischaemic cardiomyopathies. Eur Heart J 26(15): 1461-1474.

8. White JA, Patel MR (2007) The role of cardiovascular MRI in heart failure and the cardiomyopathies. Magn Reson Imaging Clin N Am 15(4): 541-564.

9. Cobb LA, Kramer RJ, Finch CA (1960) Circulatory effects of chronic hypervolemia in polycythemia vera. J Clin Invest 39: 1722-1728.

\begin{tabular}{|l|}
\hline \multicolumn{1}{|c|}{ Your next submission with Juniper Publishers } \\
- Quality Editorial service \\
- Swift Peer Review \\
- Reprints availability \\
- E-prints Service \\
- Manuscript Podcast for convenient understanding \\
- Global attainment for your research \\
- Manuscript accessibility in different formats \\
( Pdf, E-pub, Full Text, Audio) \\
- Unceasing customer service \\
Track the below URL for one-step submission \\
https://juniperpublishers.com/online-submission.php \\
\hline
\end{tabular}

